\title{
Analysis of braking performance for the definition of emergency braking intervention in ATP systems
}

\author{
M. Malvezzi, F. Bartolini, M. Rinchi \& A. Rindi \\ Department of Energetics 'S. Stecco', University of Florence, Italy
}

\begin{abstract}
A traffic management system is generally based on a set of supervision curves relating the permitted velocity of the train to the running distance, in order to ensure the respect of speed restrictions on the line by intervention of an emergency braking in case of train velocity exceeding the permitted one. The basic braking model defines a deceleration profile, which represents the train nominal braking performance, used to determine the stopping distance and to compare it with the available distance. This deceleration profile value has to be reduced using properly defined safety coefficients.

The paper describes the method that allows one to calculate the safety coefficient as a function of the safety target (in terms of probability of failure). The method is based on the braking performance probability distribution estimation, expressed as the ratio between the real and the nominal deceleration. This study permits one to evaluate the probability that the real deceleration is smaller than the one used in the basic braking model and then that the real stopping distance is longer than the one calculated by the braking model. This model can then be used to tune the value of the safety margin in order to obtain a certain probability of system failure.

The numerical procedure used to simulate the braking performance is based on the Monte Carlo method, which is a method for iteratively evaluating a deterministic model using sets of random numbers as inputs. This method is often used when the model is complex, nonlinear, or involves several parameters.
\end{abstract}

Keywords: deceleration distribution, Monte Carlo, safety margins. 


\section{Introduction}

The operation of traffic on a railway network necessitates a good control of the stopping behaviour of the trains using a signalling system. For the majority of train operations today, the main information the driver is given is via signals placed at regular intervals along the track ordering the train to stop before the danger point, for example: another train or switch. The necessity of optimising the traffic density and the new possibilities of technology have led to the design of on-board automatic train control systems that calculate, with data transmitted from the ground, the exact distance to prevent passing the danger point. The onboard automatic train control system computes a "safe" distance, represented by a "safe" curve function of the train speed, beyond which the train is not allowed to run. In case of a predicted overrun, emergency braking is initiated.

A new approach using modern probabilistic methods to determine unified safety margins on emergency braking [6,7] has been developed by the authors in collaboration with the UICb126-15 C group.

The braking curves are calculated on the basis of a braking model, that calculates train deceleration on the basis of some parameters (time, braking weight percentage, speed etc.). The deceleration used for the definition of the braking curves has to be 'safe', in other terms it has to assure that the actual braking performance of the train will be sufficient to guarantee the respect of the objective speed.

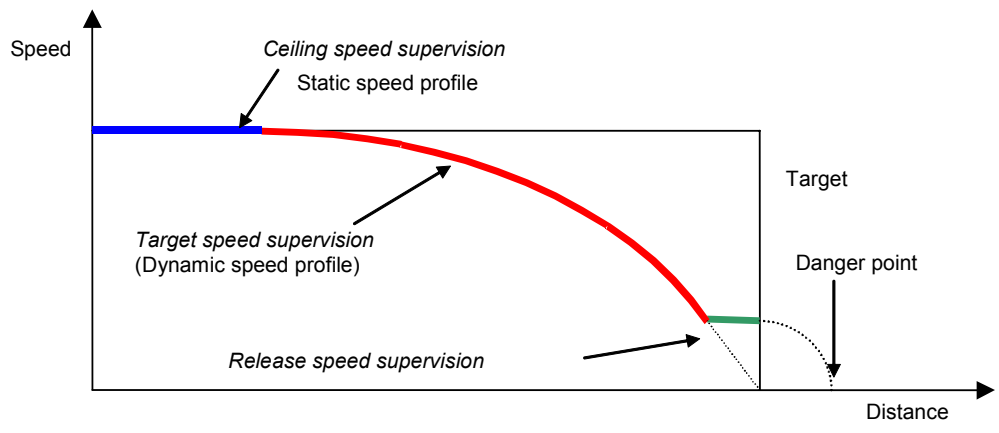

Figure 1: Example of a braking curve.

In general the deceleration profile during a braking can be represented as shown in Figure 2:

- an initial delay,

- a linear or step transient,

- a series of constant deceleration steps within established speed ranges.

As a particular case of that general representation, a braking model with a step transient is shown in Figure 2 b).

The basic parameters of this model are the following:

- $t_{e}$ braking equivalent time,

$-\quad d_{s}$ deceleration of fully developed braking. 


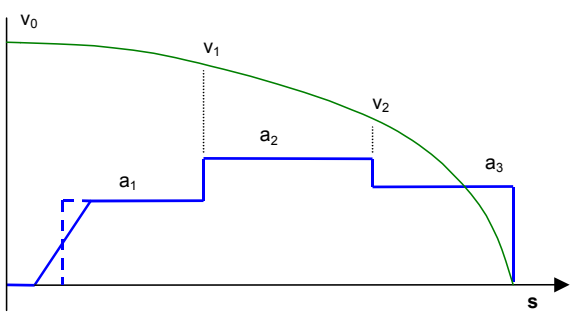

a)

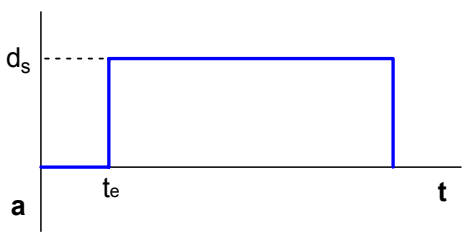

b)

Figure 2: Deceleration profile during a braking, a) deceleration steps during a braking, b) single step profile, equivalent time and safe deceleration.

For reasons of simplicity this representation refers to the situation on level track. The complete model must obviously take into account the effect of the gradient on the deceleration. The fully developed deceleration is calculated reducing the nominal deceleration $d_{0}$ (that depends on train braking properties) by a proper safety factor $k_{s}<1$.

The model described in this paper calculates the statistical distribution $p(k)$ of the ratio between the actual and the nominal deceleration $k$. Then, if a safety coefficient $k_{s}=k$ is chosen for the braking intervention curve, the probability that the actual deceleration is lower than those used to calculate the curve (in other terms the probability that the train is not able to follow the braking curve) is $p\left(k_{s}\right)$. In other terms the model allows one to relate the safety coefficient to the probability of failure and thus can be used in two ways:

- given a certain safety coefficient, it allows to calculate the associated safety level (expressed in terms of failure probability):

$$
p=p\left(k_{s}\right)
$$

- given a certain safety target (expressed as an acceptable failure rate) the corresponding safety factor can be calculated:

$$
k_{s}=k(p) \text {. }
$$

\section{Model description}

\subsection{Parameters that influence braking performance}

The actual braking performance of a train is different from the nominal one due to a number of causes. For example, the features of the braking evaluation method used to define the braked weight do not provide an absolute definition of the braking performance. The braked weight percentage corresponds to the mean stopping distance and is evaluated from a series of stopping distances that, even in nominal testing conditions (no gradient, normal efficiency of the braking system, good wheel-rail adhesion, etc.) present a certain statistical distribution. For a sufficiently high number of tests, the distribution of stopping distance can be approximated with a normal distribution. 
Even if the actual braking performance corresponds to the nominal one at the characteristic speed used for the evaluation of the braked weight, often the braked weight percentage relative to different speeds differs from the nominal one. In the case of disc brakes, usually the stopping distances for speeds higher than the nominal one are lower than those resulting from the UIC diagrams. Conversely for speeds lower than the nominal one the opposite effect can happen, however this result is not taken into account in the UIC leaflet because these stopping distances result in an additional margin with respect to the signalling distances. However, for a speed control system the actual behaviour of the braking performance, even for low speed values, has to be taken into account.

On the vehicles, in particular those equipped with disc brakes, different friction components are generally used. Their friction coefficients have to be included in the tolerance range set by the UIC leaflet. The braked weight percentage is calculated on the basis of the nominal friction coefficient and then verified by tests. However different friction elements, with a friction coefficient different than the nominal one (within the UIC tolerance), could be used in future without varying the vehicles' nominal characteristics. Moreover, the composite brake elements are sensitive to temperature. For low temperature, in particular in winter, brake performance generally decreases, but also the temperature increase of the brake elements, due to repeated braking applications, can have a negative effect on the braking performance. The composite brake elements are also sensitive to humidity, and in case of rain or snow, the friction coefficient may decrease significantly.

The functional parameters of the braking, such as the brake pressure, brake rigging efficiency, braking intervention times, may have certain variability. Furthermore, in case of disc brakes, the variability of wheel diameters due to the wear of the wheels has an effect on braking performance $[9,10]$.

The braked weight percentage of a passenger train is calculated for nominal load conditions. Therefore, the actual variability of the load has an effect on the braking performance of the train.

Wheel/rail adhesion coefficient has a sensitive effect on braking performance. Trains with a good braking performance, that requires an adhesion coefficient higher than those available on the line in wet conditions, are equipped with WSP devices that are designed to avoid the wheel locking up and to optimize braking performance [11,12].

The safety level of a UIC braking system is usually quite high; however the failure of a component has a given probability. For example, the failure of a distributor causes the loss of the braking force of the correspondent unit (vehicle or bogie). The effect of brake component failures on braking performance depends on train composition (its effect decreases as the length of the train increases).

In order to have a complete overview of braking performance the effects of all the above mentioned parameters have to be combined. The following section describes a numerical model that, given the probability distribution of the main parameters affecting braking performance, allows the calculation of the probability distribution of train deceleration. 


\subsection{Numerical procedure}

The numerical procedure used to simulate the braking performance is based on the Monte Carlo method that is a method for iteratively evaluating a deterministic model using sets of random numbers as inputs. This method is often used when the model is complex, nonlinear, or involves several parameters. The method can be summarized in the following steps:

- Step 1: Create a parametric model, $y=f\left(x_{1}, x_{2}, \ldots, x_{\mathrm{q}}\right)$.

- Step 2: Generate a set of random inputs, $x_{\mathrm{i} 1}, x_{\mathrm{i} 2}, \ldots, x_{\mathrm{iq}}$.

- Step 3: Evaluate the model and store the results as $y_{\mathrm{i}}$.

- Step 4: Repeat steps 2 and 3 for $i$ varying from 1 to $n$ (number of samples).

- Step 5: Analyze the results.

The parametric (deterministic) model has a certain number of inputs and a few equations that use those inputs to give a set of outputs (or response variables).

The inputs for the deterministic mathematical model are randomly generated from probability distributions, previously defined, to simulate the process of sampling from an actual population, the randomly generated inputs are used to evaluate the outputs of the mathematical model and the data generated from the simulation are elaborated in order to be represented as probability distributions.

In the numerical approach the distribution of each parameter can have any arbitrary distribution that can be simulated by means of Monte Carlo techniques, "logic" parameters, like failure of a vehicle braking system can be easily inserted, and complex and highly non linear models can be easily reproduced. On the other hand the minimum value of probability that can be obtained depends on the number of samples used for the simulation, and the computation burden increases as the number of samples increases.

\subsection{Parametric model description}

This section shows the application of the model to a passenger train, only the pneumatic brake is considered in this example, however the model can be modified to take into account different types of braking (magnetic, electrodynamics etc.).

The ratio between actual and nominal deceleration can be expressed as:

$$
k=\frac{d}{d_{0}}=\frac{\frac{F_{b}}{F_{b 0}}}{\frac{M}{M_{0}}},
$$

where $F_{b} / F_{b 0}$ is the ratio between the actual and the nominal braking force, relative to the entire train, while $M / M_{0}$ is the ratio between the actual and the nominal train mass. The ratio between the actual and the nominal value of the 
braking force, relative to a train composed of $n_{v}$ homogeneous vehicles is given by:

$$
\frac{F_{b}}{F_{b 0}}=\frac{1}{n_{v}} \sum_{i=1}^{n_{v}} \frac{F_{b i}}{F_{b i 0}} ;
$$

while the ratio between the actual and the nominal value of the mass, relative to a train composed of $n_{v}$ homogeneous vehicles is given by:

$$
\frac{M}{M_{0}}=\frac{1}{n_{v}} \sum_{i=1}^{n_{v}} \frac{M_{i}}{M_{i 0}} .
$$

The ratio between the actual and the nominal value of the braking force, relative to a single vehicle, can be expressed as function of the ratios between the actual and the nominal value of the parameters whose variability have been considered in the study, for example, for a passenger train:

$$
\frac{F_{b i}}{F_{b i 0}}=\frac{\frac{p_{i}}{p_{i 0}} \frac{\eta_{i}}{\eta_{i 0}} \frac{\mu_{i}}{\mu_{m e d}} \frac{\mu_{m e d}}{\mu_{0}}}{\frac{D}{D_{0}}} \cdot B_{f a i l, i} \cdot A_{i}
$$

where $p_{i} / p_{0}$ is the ratio between the actual and the nominal value of the pressure on the brake cylinders, $\mu_{i} / \mu_{\text {med }}$ is the ratio between the actual and the mean value of the brake friction coefficient, $\mu_{\text {med }} / \mu_{0}$ is the ratio between the mean and the nominal value of the brake friction coefficient, $\eta_{i} / \eta_{0}$ is the ratio between the actual and the nominal value of the brake efficiency, $D_{i} / D_{0}$ is the ratio between the actual and the nominal value of the wheel diameter, $B_{f a i l, i}$ is a coefficient that takes into account the failure of a brake component, and $A_{i}$ is a coefficient that takes into account wheel/rail adhesion conditions, defined as:

$$
A_{i}=\min \left(\frac{\rho_{i}}{\rho_{r, i}}, 1\right) .
$$

in which $\rho_{i} / \rho_{r, i}$ represents the ratio between the actual adhesion coefficient and the value required by the braking system. The "actual" adhesion coefficient $\rho_{i}$ is defined as a function of the adhesion value relative to the first vehicle, randomly extracted from a normal distribution (Figure 3), and the position of the vehicle in the train: the adhesion increasing, due to the "cleaning effect" of the wheel on the rail, is described in the model by a parabolic law defined on the basis of experimental data, as shown in Figure 4.

The adhesion required by the braking system is given by:

$$
\rho_{r, i}=\frac{d_{i}}{g}=\frac{1}{g}\left(\frac{d_{r, i}}{d_{0}}\right) d_{0}=\left(\frac{\frac{p_{i}}{p_{0}} \frac{\eta_{i}}{\eta_{0}} \frac{\mu_{i}}{\mu_{m e d, i}} \frac{\mu_{\text {med }, i}}{\mu_{0}}}{\frac{M}{M_{0}} \frac{D}{D_{0}}}\right) d_{0}
$$




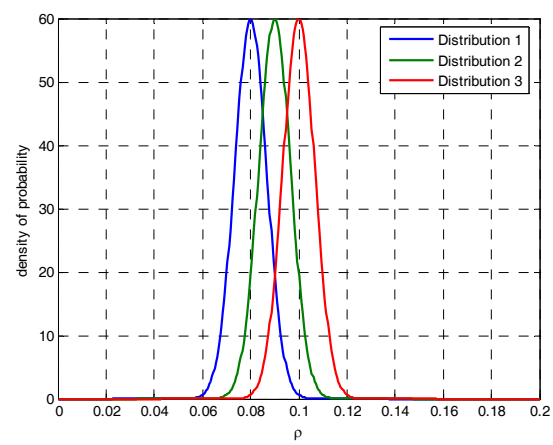

Figure 3: Available adhesion coefficient: probability density functions for the chosen distributions.

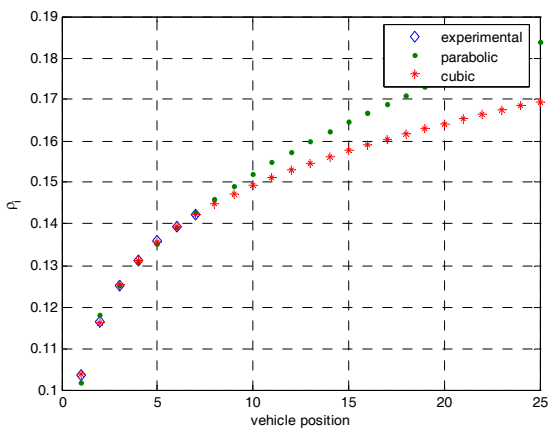

Figure 4: Reference adhesion increase along the train (relative to SNCF tests), extrapolation obtained with a parabolic and a cubic law.

where $d_{r, i}$ represents the deceleration that the train would have in case of good adhesion conditions, that depends on the values assumed by the other parameters.

\subsection{Numerical procedure}

Given the probability distributions of the parameters affecting braking performances, the developed algorithm extracts from them random numbers and combines them, according to the mathematical model described in the preceding section, in order to obtain the deceleration value of a "simulated" train. This computation is repeated, for each train type and each train length, for a very high number of samples, up to $10^{9}$. At the end of the simulation then, for each test a set composed by $10^{9}$ "virtual" trains is generated. The obtained results are then analyzed and the probability distribution of the ratio between the actual and the nominal deceleration can be found. 


\section{Applications and result discussion}

As an example the results obtained simulating a high speed train composed of 8 vehicles are described in this section. Table 1 summarizes the parameters selected for the simulation. Table 2 and Figures 7 and 8 summarizes the results obtained in terms of $k$ values. The results can be used to relate the safety coefficient to the failure probability, as it can be seen, for low probabilities

Table 1: $\quad$ Parameters for the simulation.

\begin{tabular}{|c|c|c|c|c|}
\hline Variable & Distribution & Mean & $\begin{array}{c}\text { Standard } \\
\text { deviation or } \\
\text { range }\end{array}$ & Notes \\
\hline \multicolumn{5}{|c|}{ Track properties } \\
\hline gradient & \multicolumn{4}{|c|}{ Not taken into account } \\
\hline $\begin{array}{c}\text { First vehicle } \\
\text { adhesion }\end{array}$ & Normal & 0.09 & 0.005 & \\
\hline $\begin{array}{l}\text { Adhesion } \\
\text { increasing }\end{array}$ & \multicolumn{4}{|c|}{ (derived from experimental data- parabolic law) } \\
\hline $\begin{array}{c}\text { Degraded/good } \\
\text { adhesion } \\
\text { conditions } \\
\end{array}$ & \multicolumn{4}{|c|}{$20-80 \%$} \\
\hline $\begin{array}{c}\begin{array}{c}\text { Number of } \\
\text { vehicles }\end{array} \\
\end{array}$ & Deterministic & \multicolumn{2}{|c|}{8} & \\
\hline $\begin{array}{c}\text { Nominal } \\
\text { deceleration }\end{array}$ & Deterministic & \multicolumn{2}{|c|}{$1.3 \mathrm{~m} / \mathrm{s}^{2}$ (high pressure) } & \\
\hline Mass & Normal & 1 & 0.013 & $\begin{array}{c}\text { The same value for } \\
\text { the whole train }\end{array}$ \\
\hline Pressure & Normal & 1 & 0.02 & $\begin{array}{c}\text { One value for each } \\
\text { bogie }\end{array}$ \\
\hline Efficiency & Uniform & 0.975 & $\begin{array}{c}-0.025+ \\
0.025\end{array}$ & $\begin{array}{c}\text { The same value for } \\
\text { the whole train }\end{array}$ \\
\hline Friction & Normal & 1 & 0.015 & $\begin{array}{c}\text { One value for each } \\
\text { bogie }\end{array}$ \\
\hline Mean friction & Normal & 0.95 & 0.045 & $\begin{array}{c}\text { The same value for } \\
\text { the whole train }\end{array}$ \\
\hline Wheel diameter & Uniform & 0.97 & $-0.03+0.03$ & $\begin{array}{c}\text { The same value for } \\
\text { the whole train }\end{array}$ \\
\hline $\begin{array}{l}\text { Failure } \\
\text { probability }\end{array}$ & \multicolumn{3}{|c|}{$10^{-6}$} & $\begin{array}{c}\text { The failure is } \\
\text { applied to a single } \\
\text { bogie }\end{array}$ \\
\hline $\begin{array}{l}\text { Partial brake } \\
\text { failure }\end{array}$ & \multicolumn{3}{|c|}{$10^{-5}$ for the high pressure stage } & \\
\hline
\end{tabular}

Table 2: $\quad k$ ratio and deceleration as a function of probability.

\begin{tabular}{|c|c|c|c|c|c|c|c|c|}
\hline probability & $1.0 \mathrm{E}-$ & $1.0 \mathrm{E}-$ & $1.0 \mathrm{E}-$ & $1.0 \mathrm{E}-$ & $1.0 \mathrm{E}-$ & $1.0 \mathrm{E}-$ & $1.0 \mathrm{E}-$ & $1.0 \mathrm{E}-$ \\
08 & 07 & 06 & 05 & 04 & 03 & 02 & 01 \\
\hline $\mathrm{k}$ & 0.5873 & 0.6023 & 0.6230 & 0.6465 & 0.6728 & 0.7029 & 0.7411 & 0.8083 \\
\hline $\begin{array}{c}\text { deceleration } \\
\left(\mathrm{m} / \mathrm{s}^{2}\right)\end{array}$ & $\begin{array}{c}0.7634 \\
9\end{array}$ & $\begin{array}{c}0.7829 \\
9\end{array}$ & 0.8099 & $\begin{array}{c}0.8404 \\
0\end{array}$ & $\begin{array}{c}0.8746 \\
4\end{array}$ & $\begin{array}{c}0.9137 \\
7\end{array}$ & $\begin{array}{c}0.9634 \\
3\end{array}$ & $\begin{array}{c}1.0507 \\
9\end{array}$ \\
\hline
\end{tabular}




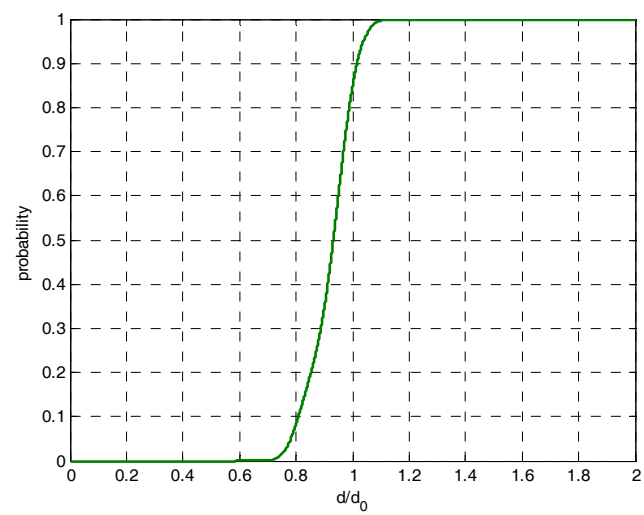

Figure 5: $\quad$ Simulated train, probability distribution of the ratio $\mathrm{d} / \mathrm{d}_{0}$.

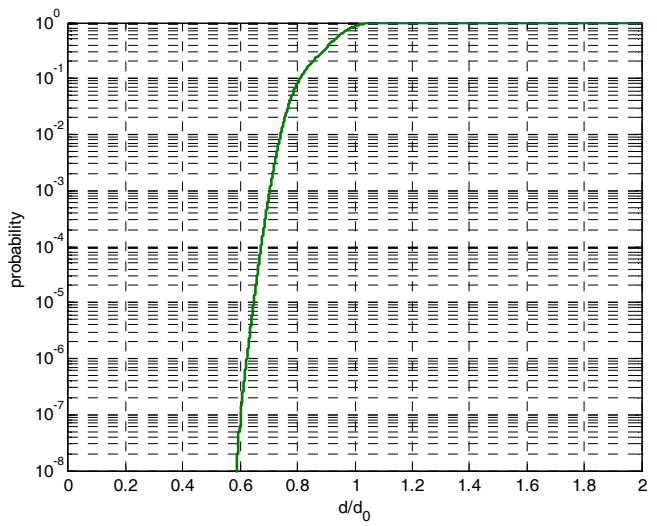

Figure 6: Probability distribution of the ratio $\mathrm{d} / \mathrm{d}_{0}$ on a logarithmic diagram.

\section{Conclusions}

The method briefly presented above gives an overview of the possibilities of the probabilistic way to evaluate safety margins in order to guarantee an emergency braking performance or deceleration. This approach can offer a large number of advantages. First of all it gives the possibility to quantify the margins depending on the respect of a safety target (that is the probability to stop before the danger point). Furthermore the results are linked with the physical train brake characteristics, the reliability of its brake system and the precision of its brake performances. Thus, a train whose brake system is classified as high quality (in terms of reliability and efficiency) can benefit from narrower safety margins and a better emergency curve in the signalling system. Finally, the results can be compared with statistical on line data. 


\section{References}

[1] P. Presciani: "Studio di un modello di frenatura per sistemi di controllo della velocità" (Research on a braking model for speed control systems), Ingegneria Ferroviaria No. 8/2000.

[2] ERRI B 126 RP 30 "Existing and future train control and command systems on the European railways - Models for deceleration curves", April 2001.

[3] "Description of the brake curve calculation", Ref. EEIG-ERTMS: 97E881 version $5 \mathrm{D}, 2 / 7 / 2001$.

[4] UIC B126-15 C Working Group, Braking questions: Safety margins for continuous speed control systems on existing lines and migration strategies for ETCS/ERTMS, ERRI B 126/DT 407 3rd draft November 2004.

[5] UIC B126-15 C Working Group, Braking questions: Methodology for the safety margin calculation of the emergency brake intervention curve for trains operated by ETCS/ERTMS, UIC B 126 /DT 414, June 2006.

[6] Presciani, P., Malvezzi, M., Bonacci, G. L. and Balli, M. Development of a braking model for a speed supervision system. In World Congress on Railway Research (WCRR2001), November 2001.

[7] M. Malvezzi, B. Allotta, P. Presciani, P. Toni "Probabilistic Analysis of Braking Performance in Railways", Proc. of the IMechE, Journal of Rail and Rapid Transit, vol. 217 Part F, September 2003, pp.149-165.

[8] Brakes-Braking Power, Leaflet UIC 544-1, 3rd edition, Reprint dated 1979.

[9] Brakes-Disc Brakes and Disc Brake Pads - General Conditions Governing Bench Tests, Leaflet UIC 541-3, 4th edition, 1993.

[10] Brakes-Brakes with Composition Brake Blocks, Leaflet UIC 541-4, 2nd edition, 1990.

[11] Frein-L'anti-enrayeur, Leaflet UIC 541-05, 2nd edition, 2004.

[12] M. Boiteux, M. Cadier, J. Kling, W. Kunnes, Synthese des Connassainces Theoriques et Pratiques Relaives a l'Adherence degradee et Acquises depuis a la Parution du RP 2 du Comite ORE B164, ORE DT 257 (B164), Utrecht, Juillet 1992. 